\title{
A Novel Isolated Quazi Z-Source DC-DC Converter
}

\author{
Wenxu Si, Shan Li, Yan Chen, and Sen Cui
}

\begin{abstract}
The isolation quasi-Z-source converter is a new type of converter based on the conventional non isolated quasi-Z-source converter. Compared with the traditional converter into the isolation transformer, the topology has the advantages of simple structure, which not only reduces the number of switching devices, reduce costs, and reduce the voltage of each period in $Z$ network stress, reduce the converter volume. The topology can in low voltage input, output arbitrary voltage value, further improve the energy transfer efficiency. Based on the analysis of the original converter, this paper introduces the structure of the isolated quasi $Z$ source converter, and analyzes its working principle; secondly build isolation quasi-Z- source and the circuit simulation model of open loop simulation in PSIM software; the simulation results consistent with the theoretical value, verify the correctness of the theoretical analysis.
\end{abstract}

Index Terms-Isolation transformer, Quasi-Z-source, DC-DC converter, the simulation analysis.

\section{INTRODUCTION}

At present, the traditional DC-DC topology is divided into two categories: one is the non isolated topology, such as Buck type, Boost type, Cuk type, Zeta type topological structure; the other is the isolation topology, such as forward circuit, flyback circuit, push-pull circuit topology structure. Although the research on the above the topology of the technology is relatively mature, but because of its single structure in complex applications, its application is limited. So we need a new topology to solve the DC-DC in production, life need. Therefore, some scholars use the $\mathrm{Z}$ network structure to solve the theoretical defects.

Z source network structure [1], as shown in Fig. 1, was proposed by Professor Peng Fangzheng in 2003, because of its unique network and allows direct state of existence, was widely used in switching power supply area. For the $Z$ source network, because $Z$ network source capacitor voltageis higher, resulting in electric volume and cost high capacity is limited; boost converter; the impact of starting circuit, easy to damage the devices and other reasons, by limiting the $\mathrm{Z}$ source structure in the switching power supply.

In 2008 , based on $Z$ source network structure of the quasi-Z-source structure [2] is proposed, as shown in Fig. 2, relative to the $Z$ network structure, it just changed the

Manuscript received September 19, 2016; revised November 14, 2016. This work was supported in part by National Natural Science Foundation of China (Grant No. 51607020), and the Basic and Frontier Research Program of Chongqing Municipality (cstc2016jcyjA0324, cstc2015jcyjA70013);

The authors are with the School of Electrical and Electronic Engineering, Chongqing University of Technology, Chongqing, 400054, China. They are also with Chongqing Energy Engineering Technology Research Center of the Internet, Chongqing, 400054, China (e-mail: svenxu@foxmail.com, lishan@cqut.edu.cn, chenyan@cqut.edu.cn,511739667@qq.com). capacitance and inductance of the position, to a certain extent reduces the voltage stress. Part of the device for the whole system still exist some device high voltage stress current, intermittent input, start impact, while the lack of electrical isolation.

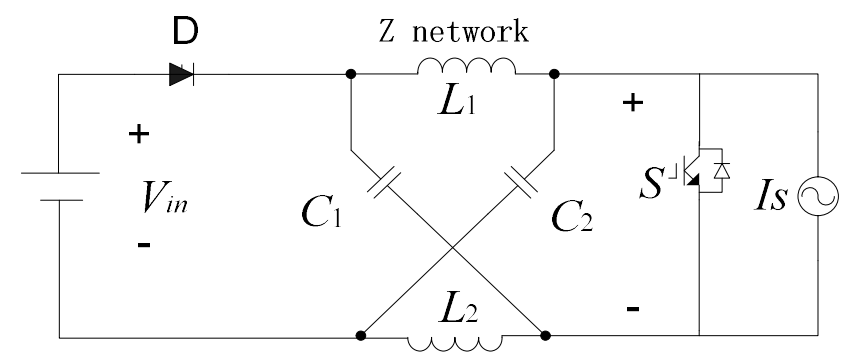

Fig. 1. Equivalent circuit of $Z$ source.

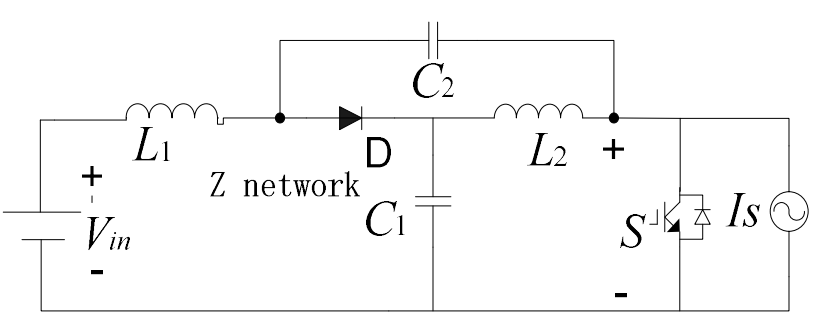

Fig. 2. Equivalent circuit of quasi-Z-source.

In order to solve the problem of quasi-Z-source exists in the work process, the isolation quasi-Z- source is based on the quasi-Z-source, its structure is added isolation transformer based on quasi-Z- source, the output changes exponentially, in the same output can greatly reduce the voltage of each element in the $\mathrm{Z}$ network the stress, thereby reducing the cost of the whole system and the volume required. The input voltage is low, such as photovoltaic power generation, wind power generation, the battery voltage output can very good need. Therefore, the isolation of quasi-Z-source is used more and more widely.

In ref. [3]-[5], Z source network application in the DC-DC converter, provides a new idea and theory for the study of the DC-DC converter. Compared with the conventional topology, $\mathrm{Z}$ source topology without pre-stage boost or buck circuit, increase a capacitor inductance L1, L2 and C1. C2 Z source network literature; Ref. [6] will quasi-Z-source network used in the DC-DC converter; Ref. [7] put forward two grade Z-source bidirectional DC converter. Ref. [8], [9] proposed the application of isolated quasi-Z-source DC-DC converter in photovoltaic power generation , the topological structure as shown in Fig. 3, the isolated quasi-Z-source is applied to DC-DC converter, compared with the quasi-Z-source greatly reduces the voltage stress of devices, reduce the converter volume. But because the structure is relatively complex, the switching device is relatively large, to control the inconvenience. 


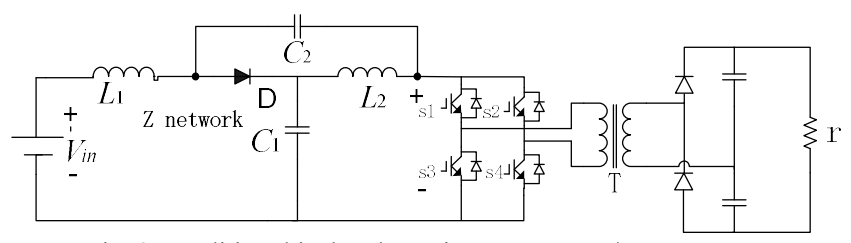

Fig. 3. Traditional isolated quasi -Z-source DC/DC converter.

This paper proposes the structure of quasi-Z-source DC-DC converter in the traditional isolation on the application of the topology in DC-DC, which was verified by PSIM simulation software. This isolation quasi-Z-source topology can provide a wider range of output voltage, the output voltage of high quality, simple structure, stable performance, reaction high sensitivity and high precision pressure regulator.

\section{THE ISOLATION Z SOURCE DC-DC CONVERTER}

\section{A. The Principle Diagram}

The isolation quasi-Z-source converter composed of a unique quasi-Z-source network and isolation transformer, the main circuit is shown in Fig. 4. The $\mathrm{Z}$ source network consists of two identical inductance L1, capacitance $\mathrm{C} 1$ and L2, the same $\mathrm{C} 2$, the quasi $\mathrm{Z}$ source topology changes the voltage through the switching of the switch tube. And then through the isolation transformer to achieve the voltage rise and decrease. And obtain the required DC voltage through rectification.

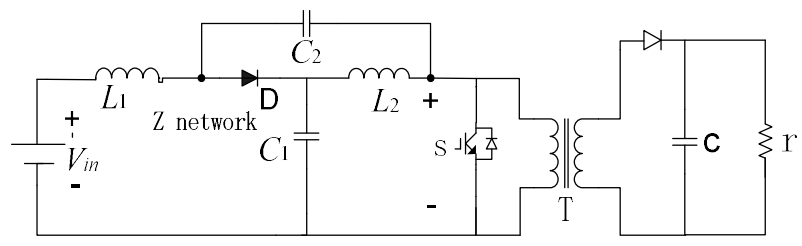

Fig. 4. A novel isolated quasi-Z-source DC/DC converter.

\section{B. Working Principle}

In [10], we can know that for the quasi-Z-source structure, there are two kinds of working states in one switching period: shoot through state and non-shoot through state.

When the quasi-Z-source network works in the shoot through state of the switch, the capacitor discharge supplies the load, the power supply and the capacitor are charged at the same time as the inductor, the diode is subjected to reverse voltage, and the equivalent circuit is shown in Fig. 5(a).

When the quasi-Z-source network works in the non-shoot through state of the switch, the inductive discharge, the power supply and the inductance are simultaneously supplied to the load and the capacitor, and the diode is forward conducting. The equivalent circuit is shown in Fig. 5(b).

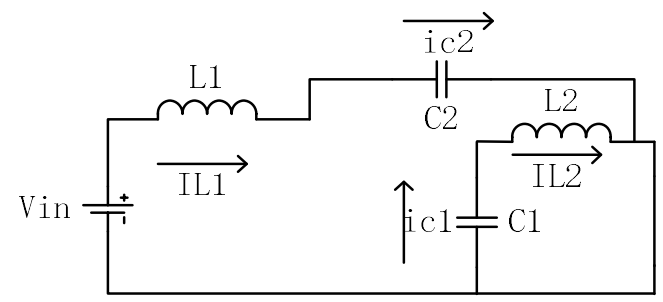

(a) Shoot-through state

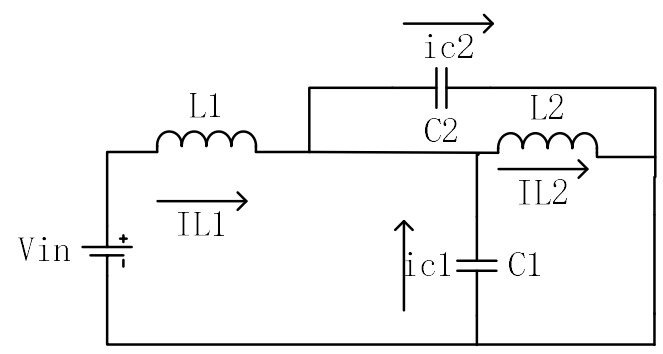

(b) Nonshoot-through state.

Fig. 5. Equivalent circuit of quasi-Z-source converter.

Suppose that a switch cycle to $T$, which through time as the T0, not through time for $T_{1}, T=T_{0}+T_{1}$.

The T0 time period, by Fig. 5(a) available:

$$
\left\{\begin{array}{l}
V_{L 1}=V_{i n}+V_{C 2} \\
V_{L 2}=V_{C 1} \\
V_{d c}=0
\end{array}\right.
$$

Among them, the $V_{d c}$ is $d c$ bus voltage peak.

In the $T_{1}$ time period, by Fig. 5(b) available:

$$
\left\{\begin{array}{l}
V_{L 1}=V_{i n}-V_{C 1} \\
V_{L 2}=-V_{C 2} \\
V_{\mathrm{dc}}=V_{C 1}-V_{L 2}=V_{C 1}+V_{C 2}
\end{array}\right.
$$

When the steady state, in a cycle, both ends of inductive voltage is 0 , the volt-second balance law available:

$$
V_{L 1}=\frac{T_{0}\left(V_{i n}+V_{C 2}\right)+T_{1}\left(V_{i n}-V_{C 1}\right)}{T}=0
$$

$$
V_{L 2}=\frac{T_{0}\left(V_{C 1}\right)+T_{1}\left(-V_{C 2}\right)}{T}=0
$$

Then:

$$
\left\{\begin{array}{l}
V_{C 1}=\frac{T_{1}}{T_{1}-T_{0}} V_{i n} \\
V_{C 2}=\frac{T_{0}}{T_{1}-T_{0}} V_{i n}
\end{array}\right.
$$

Make Shoot-through duty ratio $D, D=\frac{T_{0}}{T}$, then.

$$
\begin{gathered}
\left\{\begin{array}{l}
V_{C 1}=\frac{1-D}{1-2 D} V_{\text {in }} \\
V_{C 2}=\frac{D}{1-2 D} V_{\text {in }}
\end{array}\right. \\
V_{\mathrm{dc}}=V_{C 1}+V_{C 2}=\frac{T}{T_{1}-T_{0}} V_{\text {in }}=\frac{1}{1-2 D} V_{\text {in }}=B V_{\text {in }}
\end{gathered}
$$


Among them, B shall prevail Z source converter step-up factor.

In [10], we know, the dc voltage is discontinuous unipolar pulse voltage. Therefore, it can serve as the input voltage into the transformer primary side, Through the ratio $n=N_{S} / N_{P}$, to change the input voltage. The rectifier output voltage transformer secondary side, can get the required dc voltage.

The voltage transformer secondary side is:

$$
V_{S}=n V_{d c}
$$

The output de voltage is:

$$
V_{\mathrm{o}}=n V_{d c}=\frac{n}{1-2 D} V_{\text {in }}
$$

\section{Circuit Parameter Design}

In the $\mathrm{Z}$ network, only two kinds of inductors and capacitors, in order to simplify the circuit structure, select the same inductance and capacitance, so only need to analyze one of their respective, and the other to take the same value.

For inductors, the tube through the storage state in the switch, and the switch through electric non released state. The value should note the following points: (1) the inductance value can not be too small, otherwise it will cause energy shortage, resulting in non direct current discontinuities appear under the state the converter, from the continuous state into the discontinuous state, increasing the complexity of the control system. (2) the inductor current ripple as little as possible, this requires that the inductance value can not be too small. (3) as far as possible to reduce system loss, volume and quality. So based on the above points, the inductance values should be to meet the operating characteristics and the stability of as small as possible.

Assumptions, the ripple current $20 \%$ of the rated current. By [6], inductance calculation formula:

$$
\begin{gathered}
L=\frac{\Delta \mathrm{t}}{\Delta I} V_{L} \\
\Delta I=I \times r \\
\Delta \mathrm{t}=\frac{D}{f}
\end{gathered}
$$

Among them, the $D$ is duty cycle, $f$ is the switching frequency, and $I$ is the average value of the inductor current in steady state.

The capacitance, the main role is to absorb the current ripple and smooth voltage. Selection should be in meet the pressure and voltage ripple at the same time cannot be too small, otherwise it will increase the inductance value to meet the demand of [11]. Capacitance attenuation $\mathrm{C}$ can be calculated by the following formula:

$$
C=\frac{\Delta t}{\Delta V_{c}} \times I_{c}
$$

\section{THE SimULATION ANALYSIS}

In order to further verifies the correctness of the above theoretical analysis. In PSIM software, as shown in Fig. 4 isolation type $Z$ source circuit topology building simulation model. Assume that Vin $=50 \mathrm{v}$, the inductance $L_{1}=L_{2}=50 \mathrm{uH}$, the capacitor $C_{1}=C_{2}=150 \mathrm{uF}$, the work frequency of the switch tube $F=100 \mathrm{kHz}$, duty ratio $D=0.2$, transformer than n equals 2 , filter capacitance $C_{f}=1.2 \mathrm{mf}$, load resistance $R=10 \Omega$, simulation circuit is shown in Fig. 6.

In order to verify the correctness of the theoretical analysis. In PSIM software, in accordance with modle is shown in Fig. 4 the isolation quasi-Z-source topology is built. The simulation model assumes that the input DC voltage of $50 \mathrm{~V}$, inductance $L_{1}=L_{2}=50 \mathrm{uH}$, capacitance $C_{1}=C_{2}=150 \mathrm{uF}$ switch frequency $f=100 \mathrm{kHz}$, the duty ratio $d=0.2$, transformer the ratio $N=2$, the filter capacitor $C_{f}=1.2 \mathrm{mf}$, load resistance in $r=10 \Omega$, simulation of the circuit shown in Fig. 6 .

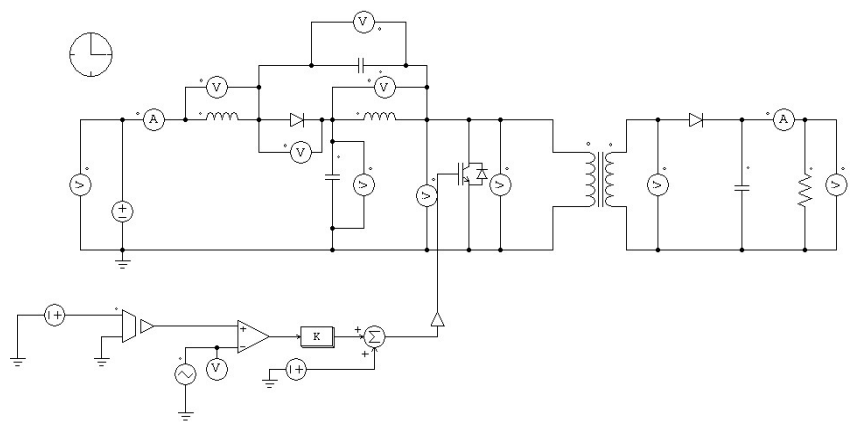

Fig. 6. Simulation circuit of isolated quasi-Z-source converter.

The pulse signal with a duty cycle of 0.2 is determined, which is to control the turn-on and turn off of the switch. The simulation results are shown in Fig. 7.

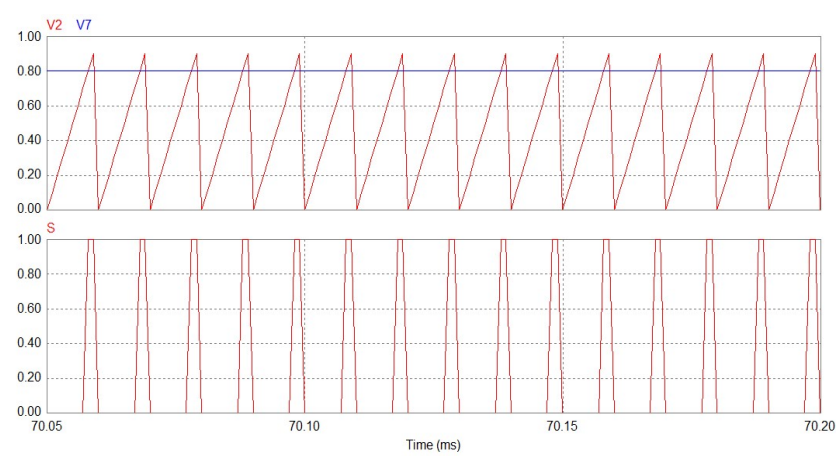

Fig. 7. Simulation results of pulse.

Simulation can be made according to the above parameters:

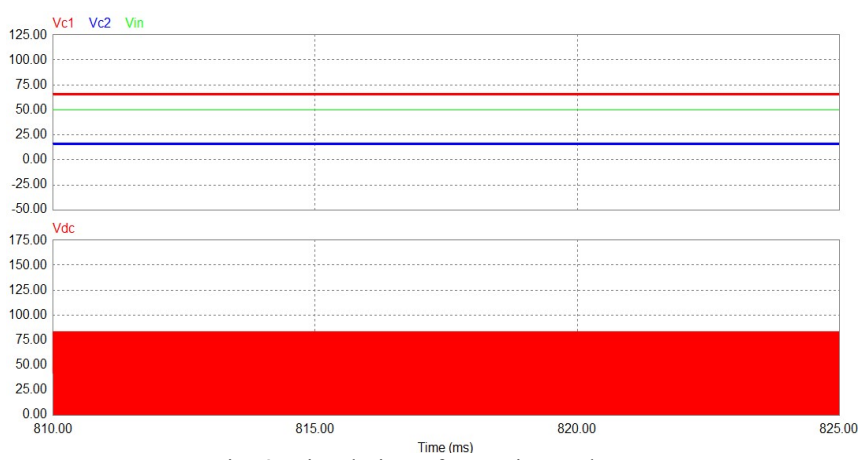

Fig. 8. Simulation of capacitor voltage. 
When the $V_{\text {in }}=50 \mathrm{~V}, D=0.2$, The Fig. 8 shows that the $V_{c 1}=66.7 \mathrm{~V}, V_{\mathrm{c} 2}=16.7 \mathrm{~V}, V_{\mathrm{dc}}=83.3 \mathrm{~V}$, and according to the theoretical analysis, the introduction of theoretical value is $V_{c 1}=66.7 \mathrm{~V}, \quad V_{\mathrm{c} 2}=16.7 \mathrm{~V}, \quad V_{\mathrm{dc}}=83.3 \mathrm{~V}$, which shows the correctness of the theoretical analysis.

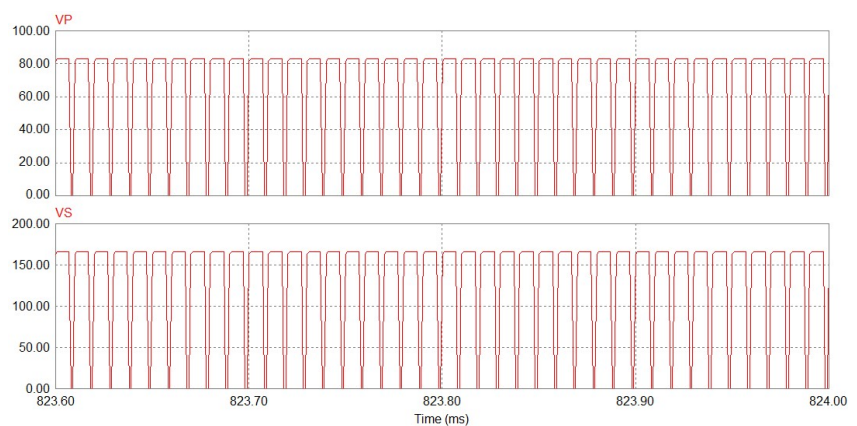

Fig. 9. Simulation of voltage at both ends of the transformer.

Fig. 9 shows the voltage waveform at both ends of the transformer.

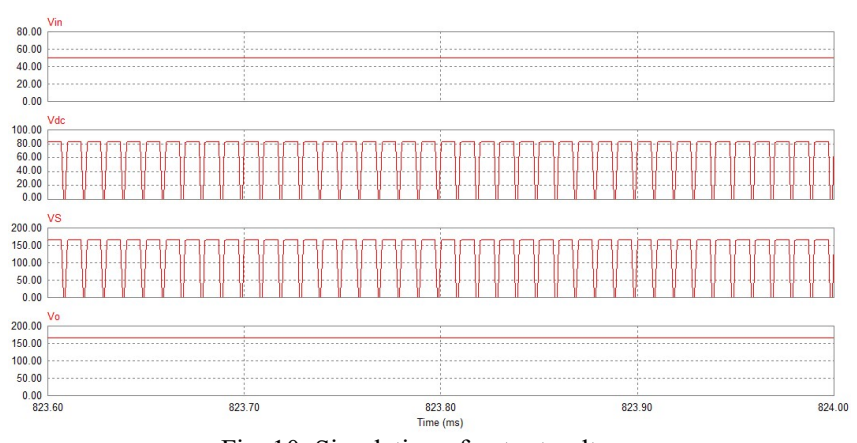

Fig. 10. Simulation of output voltage.

Fig. 10 shows that the $V_{0}=166 \mathrm{~V}$. It can be deduced from the theoretical value of the output voltage according to the above mentioned parameters, and the simulation results are basically consistent with the theoretical derivation of $V_{0}=166.7 \mathrm{~V}$.

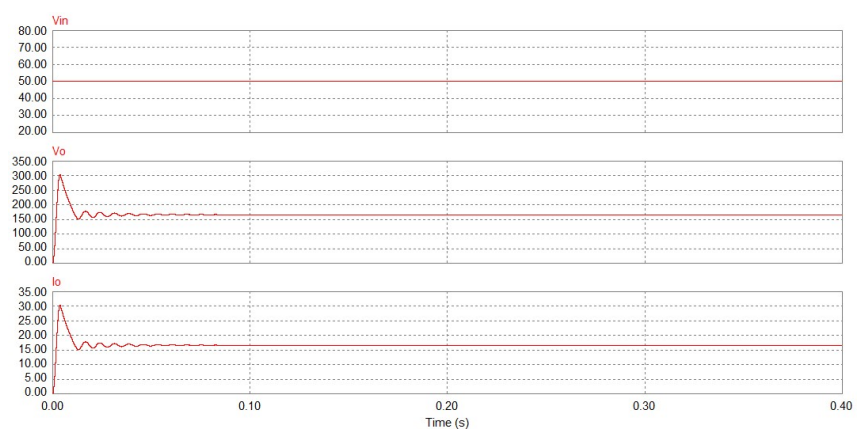

Fig. 11. Simulation results of load voltage and current.

Fig. 11 shows that the simulation results of the load voltage and current are consistent with the theoretical results, and then verify the correctness of the theoretical derivation.

By the traditional isolation quasi-Z-source converter shown in Fig. 3 comparative analysis, the novel isolated quasi-Z-source converter topology, reduces the number of switches, which can avoid the complex control signals, the control is relatively simple. Because the topology structure still retains the $\mathrm{Z}$ source network therefore, it still has the advantages of quasi-Z-source inverter with transformer added At the same time, but also makes the whole system to realize the characteristics of electrical isolation.

\section{CONCLUSION}

The novel isolated quasi-Z-source $\mathrm{dc} / \mathrm{dc}$ converter is compared with the traditional isolated quasi- Z-source converter or non-isolated converter has the following advantages: (1) in the same duty cycle, the output voltage is more arbitrary, only need to change the voltage ratio can output the required voltage value; (2) relative to the traditional isolation reduce the number of converter switching devices, reduce the system volume and the cost is reduced; (3) isolation quasi-Z-source network not only has the advantages of quasi-Z-source converter, but also it realizes the electrical isolation. (4) due to the use of $X$ type $Z$ source network is unique, integrates the characteristics of non-isolated circuit. The circuit has the advantages of simple structure, stable performance. It can meet the special needs of some, it has good application value.

\section{REFERENCES}

[1] F. Z. Peng, "Z-source inverter," IEEE Transactions on Industry Applications, vol. 39, pp. 504-510, Feb. 2003.

[2] J. Anderson and F. Z. Peng, "Four quasi-Z-source inverters," in Proc. PESC '08 IEEE, Power Electronics Specialists Conference, pp. 2743-2749, June 2008.

[3] L. M. Wang, Z. M. Qian, and F. Z. Peng, "Z-source DC inverter," Electrotechnical Application, vol. 24, no. 2, pp. 123-125, 2005.

[4] Q. D. Shang, "Z source network application in DC-DC converter," Electronics World, vol. 2, pp. 51-52, 2013.

[5] L. M. Wang, "Research on Z-source DC/DC converter," Master dissertation, College of Electrical Engineering, Zhejiang University, Hangzhou, China, 2006

[6] L. Z. Wu, W. J. Wei, and X. P. Ding, "Modeling and control of a quasi-Z-source DC-DC converter," Industrial Control Computer, vol. 27, no. 3, pp. 132-137, 2014

[7] L. T. Yang and X. H. Fu, "Design and simulation of two level quasi-source bidirectional DC-DC converter," Electronic Design Engineering, vol. 24, no. 21, pp. 90-94, Dec. 2013.

[8] D. Vinnikov and I. Roasto, "Quasi-Z-source-based isolated DC/DC converters for distributed power generation," IEEE Transactions On Industrial Electronics, vol. 58, no. 1, pp. 192-201, Jan. 2011.

[9] A. Chub, D. Vinnikov, and T. Jalakas, "Galvanically isolated Quasi-Z-source DC-DC converters with combined energy transfer for renewable energy sources integration," in Proc. the IEEE International Conference on Industrial Technology, vol. 6, pp. 2896-2900, 2015.

[10] A. Chub and D. Vinnikov, "Single-switch galvanically isolated quasi-Z-source DC-DC converter," in Proc. 2015 IEEE 5th International Conference on Power Engineering, Energy and Electrical Drives, pp. 582-586, May 2015.

[11] Z. S. Zhang and X. S. Cai, Principle and Design of Switch Power Supply (revised edition), Beijing: Publishing House Of Electronics Industry, 2004.

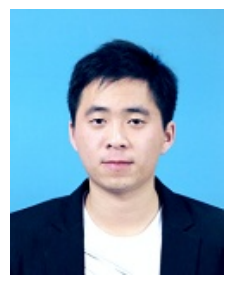

Wenxu Si received the BS degree in the School of Electrical and Information from Ningxia Institute of Science and Technology, China, in 2014. Now he is currently a master of electrical and electronic engineering, at Chongqing University of Technology, Chongqing, China. His research interests include power electronics and converter technology, the new energy power generation technology and $Z$ source inverter topology performance analysis.

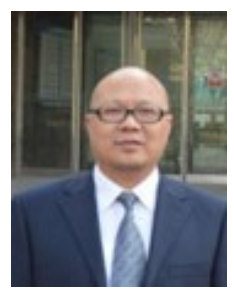

Shan $\mathrm{Li}$ received the BS degree in industrial electrical automation from Hunan University, China, in 1985 , received the MS degree in electric power transmission and automation from Xian University of Technology, China, in 1992, and received PhD degree in School of Electrical Engineering from Chongqing University, Chongqing, China, in 2009. Now he is a professor in School of Electrical and Electronic Engineering, Chongqing University of Technology. And the dean of the School of Electrical and Electronic Engineering of CQUT from 2013 
to the present. His research interests include power electronics and converter technology.

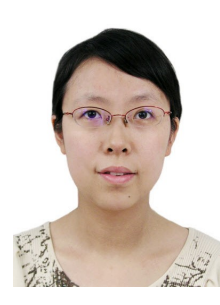

Yan Chen received the BS degree in electronics information engineering from Air Force Engineering University, China, in 2005, received the MS degree in testing \& measurement technology and instrument from Chongqing University of Technology, China, in 2008, and her PhD degrees in Electrical Engineering from Chongqing University, China, in 2012. She is a lecturer in College of school of electrical and Electronic Engineering, Chongqing University of Technology. Her research interests include power electronic devices and systems and nonlinear control technology.

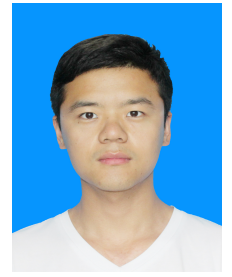

Sen Cui received the BS degree in School of electrical and information from School of Urban Science and Technology, Chongqing University, China, in 2015 , Now he is currently a master of electrical and electronic engineering, Chongqing University of Technology, Chongqing, China. His research interests include nonlinear dynamic behavior of power electronics. 